\title{
Best combination of pre-stimulation and latency period duration before cluster attachment for efficient oxytocin release and milk ejection in cows with low to high udder-filling levels
}

\author{
Shehadeh Kaskous ${ }^{1}$ and Rupert M Bruckmaier ${ }^{2 *}$ \\ ${ }^{1}$ Animal Production Department, Faculty of Agriculture, Damascus University, PO Box 30621 Damascus, Syria \\ ${ }^{2}$ Veterinary Physiology, Vetsuisse Faculty, University of Bern, Bremgartenstr. 109a, 3001 Bern, Switzerland
}

Received 12 July 2010; accepted for publication 19 October 2010; first published online 1 December 2010

Experiments were designed to investigate the suitability of a combination of a short manual teat stimulation with a short latency period before teat cup attachment to induce and maintain oxytocin release and milk ejection without interruption. In Experiment 1, seven dairy cows in mid lactation were manually pre-stimulated for 15, 30 or $45 \mathrm{~s}$, followed by either $30 \mathrm{~s}$ or $45 \mathrm{~s}$ of latency period. It was shown that all treatments induced a similar release of oxytocin without interruption until the end of milking. In particular, the latency period of up to $45 \mathrm{~s}$ did not cause a transient decrease of oxytocin concentration. In Experiment 2, milking characteristics were recorded in seven cows each in early, mid, and late lactation, respectively. Because the course of milk ejection depends mainly on the degree of udder filling, individual milkings were classified based on the actual degree of udder filling which differs between lactational stages but also between morning and evening milkings. All animals underwent twelve different udder preparation treatments, i.e. 15, 30, or $45 \mathrm{~s}$ of pre-stimulation followed by latency periods of $0,30,45$, or $60 \mathrm{~s}$. Milking characteristics were recorded. Total milk yield, main milking time and average milk flow rate did not differ between treatments if the degree of udder filling at the start of milking was $>40 \%$ of the maximum storage capacity. However, if the udder filling was $<40 \%$, main milking time was decreased with the duration of a latency period up to $45 \mathrm{~s}$, independent of duration of pre-stimulation. Average milk flow at an udder filling of $<40 \%$ was highest after a pre-stimulation of $45 \mathrm{~s}$ followed by a latency period of another $45 \mathrm{~s}$. In contrast, average milk flow reached its lowest values at a pre-stimulation of $15 \mathrm{~s}$ without additional latency period. However, average milk flow after a 15-s pre-stimulation increased with increasing latency period. In conclusion, a very short pre-stimulation when followed by a latency period up to $45 \mathrm{~s}$ before teat cup attachment remains a suitable alternative for continuous stimulation to induce milk ejection.

Keywords: Milking, pre-stimulation, latency period, dairy cow.

Between milkings the milk accumulates first in the alveolar tissue then in the cisternal compartment of the udder. After more than $10 \mathrm{~h}$ from the previous milking the milk in the cistern compartment amounts to $<30 \%$ while most of the milk $(>70 \%)$ is stored in the alveolar tissue of the udder. Only the cisternal milk is immediately available for milk removal (Knight et al. 1994; Pfeilsticker et al. 1996; Ayadi et al. 2004; Belo et al. 2009) whereas the alveolar milk is only available for the milking machine after milk ejection which occurs in response to tactile teat stimulation and

*For correspondence; e-mail: rupert.bruckmaier@physio.unibe.ch oxytocin (OT) release. The lag time from the start of stimulation until the onset of milk ejection usually lasts for 1-2 min (Bruckmaier et al. 1994; Bruckmaier \& Hilger, 2001). Timing of OT release and milk ejection before the start of milk removal is crucial for subsequent milking performance (Bruckmaier et al. 2001). Delayed milk ejection at the start of milking is indicated by transiently reduced or interrupted milk flow after removal of the cisternal milk (Bruckmaier \& Blum, 1996) or by a period of totally lacking milk flow at low udder filling if no cisternal milk is available before milk ejection commences (Bruckmaier \& Hilger, 2001). Delayed milk ejection can have negative effects on milking efficiency causing a prolonged machine-on time (Bruckmaier \& Blum, 1996). Pre-milking teat stimulation, 
either manual or by the milking machine, causes induction of alveolar milk ejection before the start of milking (Bruckmaier \& Blum, 1998; Bruckmaier, 2001).

Pre-stimulation before the start of milk removal induces an early release of OT and improves the milking characteristics during subsequent machine milking because milk ejection has already commenced when the withdrawal of milk starts (Rasmussen et al. 1992; Bruckmaier et al. 1994; Bruckmaier \& Blum, 1996; Weiss \& Bruckmaier 2005; Tancin et al. 2006). A pre-stimulation for 30-60 s before milking has been recommended to ensure immediate and continuous milk flow after cluster attachment (Mayer et al. 1985; Rasmussen et al. 1990, 1992). It has been shown that the occurrence of milk ejection is mainly a matter of duration of stimulation whereas the intensity of stimulation is of low importance (Weiss et al. 2003). The lag time from the start of stimulation until the occurrence of milk ejection depends on the degree of udder filling (Bruckmaier \& Hilger, 2001). While the release of OT from the pituitary is independent of udder filling, milk ejection in response to the released OT at the level of the udder is delayed at low udder filling (Bruckmaier et al. 1994; Bruckmaier \& Hilger, 2001). The actual degree of udder filling increases with an increasing interval since the previous milking and decreases in later stages of lactation owing to a reduced milk secretion (Bruckmaier \& Hilger, 2001). The optimal duration of pre-stimulation to get milk ejection started before the start of milking was shown to be up to $90 \mathrm{~s}$ in udders containing small amounts of milk, whereas in well-filled udders $20 \mathrm{~s}$ was sufficient (Weiss \& Bruckmaier, 2005).

Very few studies show that it can be advantageous for the subsequent milk removal if, instead of continuous stimulation, the time from the start of teat stimulation until cluster attachment is divided into a period of stimulation and a short latency period (Rasmussen et al. 1992). A pre-stimulation for $30 \mathrm{~s}$ followed by a latency time of $30 \mathrm{~s}$ before cluster attachment has positively affected both milk flow and evacuation of the udder (Bruckmaier et al. 2001). For practical milking management, a short latency period between udder preparation and start of milking can be advantageous because several animals (e.g. 3) can be prepared in a row before clusters are attached.

However, it has been shown that a latency period of 2 min or more between pre-stimulation and start of milking influences the course of milk removal negatively, i.e. causes slow and incomplete udder emptying (Mayer et al. 1984; Bruckmaier et al. 2001). Thus, if a combination of tactile stimulation and latency period should be applied, a precise adjustment of both stimulation and latency period seems to be crucial for successful milk removal.

The goal of this study was to determine optimal combinations of pre-stimulation and latency periods under consideration of the degree of udder filling, i.e. stage of lactation, under practical milking conditions. Two experiments were conducted to evaluate OT profiles and milk flow patterns at different combinations of short manual pre-stimulation and latency periods up to $1 \mathrm{~min}$ before cluster attachment.

\section{Materials and Methods}

\section{Animals and milking}

The dairy cows used in this study were of the Holstein (HF), Brown Swiss (BS) and Simmental (SI) breeds. The average lactational milk yield of the experimental herd was $8600 \mathrm{~kg}$. Experimental milkings were performed during routine milking times at 5.00 and at $16 \cdot 00$. During routine milkings and similarly during the experiments machine milking was performed after manual pre-stimulation which consisted of fore-stripping of one or two squirts of milk from each teat, washing teats with wetted single-use paper towels, and massage of teats and udder. Milkings were performed in a $2 \times 3$ tandem milking parlour at a vacuum of $42 \mathrm{kPa}$, a pulsation rate of 60 cycles/min and a pulsation ratio of 60/40. To adapt the animals to the combination of pre-stimulation and latency period, cows were milked with a combination of $30 \mathrm{~s}$ pre-stimulation and $30 \mathrm{~s}$ latency period before cluster attachment during $3 \mathrm{~d}$ before the start of the experiment.

All experimental cows were clinically healthy and in particular free of clinical mastitis. During the experimental period in September and October the cows were full-time grazed on pasture except for the milking periods. During $1 \mathrm{~h}$ after each milking time the animals received concentrates according to their individual production levels beyond $24 \mathrm{~kg} / \mathrm{d}$ provided by automatic feeders in the loose housing barn close to the milking parlour.

During all experimental milkings milk flow curves were recorded with a mobile device (Lactocorder, WMB, 9436 Balgach, Switzerland) as previously described (Bruckmaier et al. 1993). During all experimental milkings the milking characteristics as calculated by the LactoPro Software (Version 5.2.0 Beta 49 software; WMB, 9436 Balgach, Switzerland) were used for evaluation of the milk flow curves. The parameters used were total milk yield (TMY), main milking time (MMT, time from milk flow $>0.5 \mathrm{~kg} / \mathrm{min}$ at the start of milking until $<0 \cdot 2 \mathrm{~kg} / \mathrm{min}$ at the end of milking) and average milk flow during MMT (AMF).

\section{Experiment 1}

Seven cows in mid lactation (100-200 DIM) in their second to forth lactation were used to investigate the patterns of OT before and during milking after six different combinations of manual pre-stimulation and latency periods between prestimulation and cluster attachment. Each treatment was performed once in each animal at either morning or evening milking during three consecutive days. The sequence of treatments was randomly chosen for each animal to avoid confounding effects of specific milking times. The treatments were either 15, 30 or $45 \mathrm{~s}$ of manual pre-stimulation $(\mathrm{P})$, all combined with either $30 \mathrm{~s}$ or $45 \mathrm{~s}$ of latency period (L) before cluster attachment.

Indwelling catheters (Cavafix Certo Splittocan 338, Braun, 34212 Melsungen, Germany) were inserted into one jugular vein for blood sampling on the day before the start of the milking experiments. Blood samples were taken at $-60,0$ 


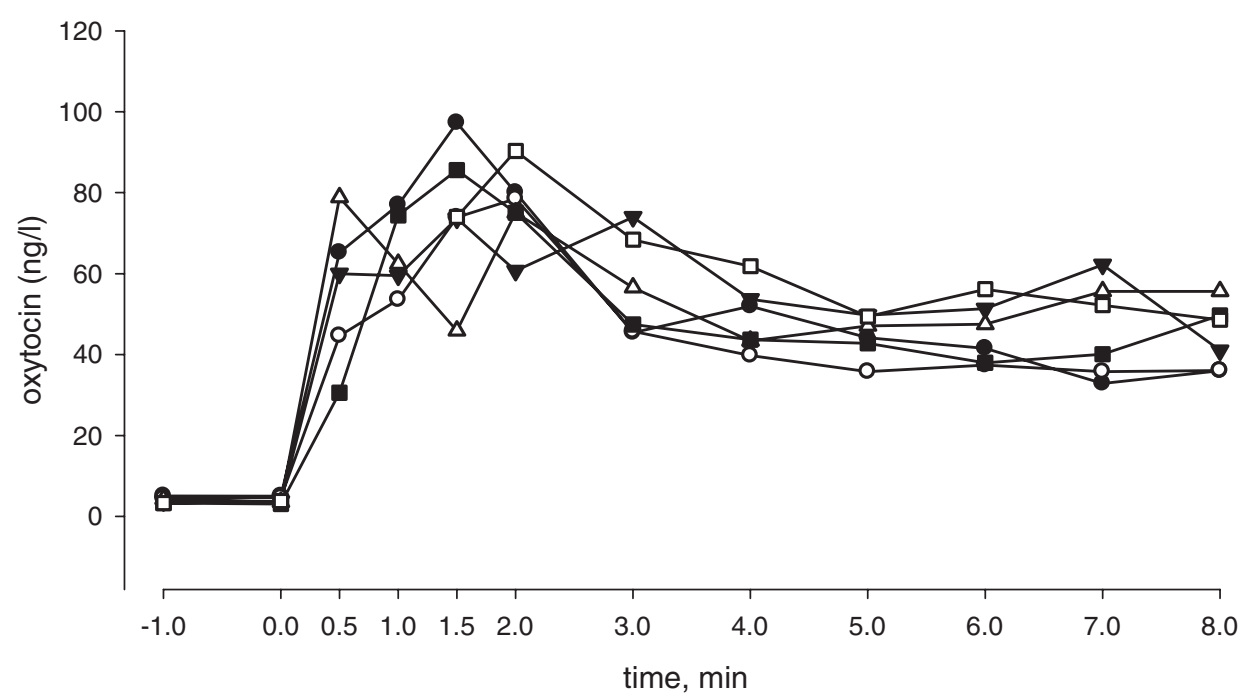

Fig. 1. Mean plasma concentration of oxytocin (ng/l) before stimulation ( -1 to 0$)$, during 6 different combinations of pre-stimulation (P) and latency (L) periods, and during subsequent machine milking. P15/L30, $\bigcirc$ P15/L45, $\boldsymbol{\nabla}$ P30/L30, $\triangle$ P30/L45, $\square$ P45/L30, $\square$ P45/L45.

(immediately before stimulation started), 30, 60, 90, $120 \mathrm{~s}$ relative to the start of pre-stimulation and further in 1-min intervals until the end of milking. To facilitate blood sampling, Experiment 1 was performed in a stanchion barn after adaptation to the different milking environment for $3 \mathrm{~d}$. All milking machine specifications were identical to those in the milking parlour.

Blood samples were prevented from coagulation by adding Na-EDTA, cooled on ice, and centrifuged at $4{ }^{\circ} \mathrm{C}$ and $3000 \mathrm{~g}$ for $15 \mathrm{~min}$. The obtained plasma was stored at $-20{ }^{\circ} \mathrm{C}$ until analysis. OT concentrations were measured by radioimmunoassay according to Schams (1983).

\section{Experiment 2}

Milking characteristics at different combinations of prestimulation and latency periods before cluster attachment were investigated in twenty-one healthy cows in different lactational stages. The animals were in their second to sixth lactation. At the start of the trial, seven animals each were in early (<100 DIM, 54 \pm 5 DIM), mid (100-200 DIM, $160 \pm 34$ DIM) and late (>200 DIM, 236 \pm 22 DIM) lactation. Twelve different treatments were performed with a prestimulation (P) of 15,30 , or $45 \mathrm{~s}$ combined with latency periods (L) of $0,30,45$, or $60 \mathrm{~s}$. The sequence of treatments was randomly assigned to each animal; however, the treatment remained the same for two consecutive milkings (morning and evening). In order to avoid influences of the lactation persistency of individual milkings, cows were classified based on the degree of udder filling at the respective milking for statistical evaluations (20-40, 40-60, 60-80 and $80-100 \%$, respectively). Udder filling was estimated as previously described (Bruckmaier \& Hilger, 2001; Weiss et al. 2002; Weiss \& Bruckmaier, 2005). Maximum storage capacity of the mammary gland $(100 \%)$ was estimated as half of the maximum daily milk yield in month 2 of the current lactation. Because of different milking intervals between morning and evening milkings each animal was classified twice, separately for morning and evening milkings.

\section{Statistical analyses}

Results are presented as means \pm SEM. For statistical testing, the SAS program package release 8.02 (SAS Institute, 1999) was used. Treatment effects of pre-stimulation time and latency period were tested for significance $(P<0 \cdot 05)$ using the MIXED procedure in SAS. For Experiment 1 the model included pre-stimulation, latency period, the interaction between pre-stimulation with latency period and animal as repeated subject. For Experiment 2 the model included effects of pre-stimulation time, latency period, udder filling class, repeated effect of cow within pre-stimulation time, and repeated effect of cow within latency period. Significant differences $(P<0 \cdot 05)$ of milk flow parameters were localized by using Bonferroni's $t$ test.

\section{Results}

\section{Experiment 1}

As shown in Fig. 1 baseline OT concentrations before the start of milking were similarly low in all treatments. Already at $30 \mathrm{~s}$ after the start of stimulation, OT has significantly increased in all treatments $(P<0 \cdot 05)$, but did not differ between treatments. OT remained elevated without any transient decrease during the latency period similarly in all treatments until the end of milking. Highest OT concentrations as means of 7 animals were reached between 0.5 and 2 min after the start of stimulation, and did not differ between treatments. Thus, OT continued to increase during the latency period after the end of pre-stimulation, and after 
Table 1. Total milk yield (TMY), main milking time (MMT), and average milk flow (AMF) at different degrees of udder filling and different combinations of pre-stimulation and latency period (Experiment 2)

Filling class

\begin{tabular}{|c|c|c|c|c|c|c|c|c|c|c|c|}
\hline & \multicolumn{2}{|l|}{$20-40 \%$} & \multicolumn{3}{|c|}{$40 \cdot 1-60 \%$} & \multicolumn{3}{|c|}{$60 \cdot 1-80 \%$} & \multicolumn{3}{|c|}{$80 \cdot 1-100 \%$} \\
\hline \multicolumn{12}{|c|}{ Number of observations } \\
\hline & 8 & & & 14 & & & 10 & & & 10 & \\
\hline \multicolumn{12}{|c|}{ Pre-stimulation, s } \\
\hline 15 & 30 & 45 & 15 & 30 & 45 & 15 & 30 & 45 & 15 & 30 & 45 \\
\hline $8 \cdot 54$ & $8 \cdot 73$ & $9 \cdot 05$ & $9 \cdot 71$ & $9 \cdot 53$ & $9 \cdot 63$ & $16 \cdot 90$ & $17 \cdot 05$ & $16 \cdot 20$ & $17 \cdot 46$ & $18 \cdot 32$ & $17 \cdot 78$ \\
\hline $8 \cdot 52$ & $8 \cdot 14$ & $8 \cdot 82$ & $9 \cdot 25$ & $10 \cdot 24$ & $9 \cdot 65$ & $16 \cdot 50$ & $17 \cdot 55$ & $16 \cdot 94$ & $17 \cdot 47$ & $17 \cdot 80$ & $17 \cdot 73$ \\
\hline $8 \cdot 03$ & $7 \cdot 99$ & $8 \cdot 25$ & $10 \cdot 54$ & $9 \cdot 35$ & $9 \cdot 34$ & $16 \cdot 83$ & $17 \cdot 71$ & $17 \cdot 01$ & $17 \cdot 94$ & $17 \cdot 75$ & $17 \cdot 32$ \\
\hline $8 \cdot 07$ & $\begin{array}{l}8 \cdot 23 \\
\text { SE } 0 \cdot 55\end{array}$ & $9 \cdot 11$ & $9 \cdot 82$ & $\begin{array}{l}10 \cdot 30 \\
\text { SE } 0.73\end{array}$ & $9 \cdot 79$ & $16 \cdot 39$ & $\begin{array}{l}17 \cdot 44 \\
\text { SE } 1 \cdot 85\end{array}$ & $16 \cdot 22$ & $18 \cdot 07$ & $\begin{array}{l}17 \cdot 56 \\
\text { SE } 1 \cdot 12\end{array}$ & $17 \cdot 30$ \\
\hline $5 \cdot 51^{\mathrm{C}}$ & $5 \cdot 01^{\mathrm{c}}$ & $5 \cdot 11^{\mathrm{c}}$ & $5 \cdot 28$ & $5 \cdot 31$ & $5 \cdot 06$ & $7 \cdot 56$ & $7 \cdot 77$ & $7 \cdot 62$ & $6 \cdot 14$ & $6 \cdot 40$ & $5 \cdot 72$ \\
\hline $4 \cdot 84^{b}$ & $4 \cdot 85^{b}$ & $4 \cdot 82^{b}$ & $5 \cdot 20$ & $5 \cdot 46$ & $5 \cdot 10$ & $7 \cdot 53$ & $7 \cdot 91$ & $7 \cdot 79$ & 5.93 & $6 \cdot 17$ & $6 \cdot 33$ \\
\hline $4 \cdot 46^{\mathrm{a}}$ & $4 \cdot 14^{\mathrm{a}}$ & $4 \cdot 18^{\mathrm{a}}$ & $5 \cdot 72$ & $5 \cdot 21$ & $5 \cdot 13$ & $7 \cdot 61$ & $7 \cdot 65$ & $7 \cdot 80$ & $6 \cdot 44$ & $6 \cdot 05$ & $6 \cdot 04$ \\
\hline $4 \cdot 65^{\mathrm{ab}}$ & $\begin{array}{l}4 \cdot 74^{\mathrm{ab}} \\
\text { SE } 0 \cdot 47\end{array}$ & $4 \cdot 75^{\mathrm{ab}}$ & $5 \cdot 38$ & $\begin{array}{c}5 \cdot 29 \\
\text { SE } 0 \cdot 33\end{array}$ & $5 \cdot 23$ & $7 \cdot 49$ & $\begin{array}{c}8 \cdot 03 \\
\text { SE } 0 \cdot 73\end{array}$ & $7 \cdot 82$ & $6 \cdot 28$ & $\begin{array}{c}5 \cdot 74 \\
\text { SE } 0 \cdot 54\end{array}$ & $5 \cdot 95$ \\
\hline $1 \cdot 45^{\mathrm{a}}$ & $1 \cdot 65^{\mathrm{ab}}$ & $1 \cdot 64^{\mathrm{ab}}$ & $1 \cdot 78$ & $1 \cdot 72$ & $1 \cdot 83$ & $2 \cdot 26$ & $2 \cdot 25$ & $2 \cdot 17$ & $2 \cdot 86$ & $2 \cdot 86$ & $3 \cdot 05$ \\
\hline $1 \cdot 68^{\mathrm{ab}}$ & $1 \cdot 64^{\mathrm{ab}}$ & $1 \cdot 76^{\mathrm{b}}$ & 1.69 & 1.79 & $1 \cdot 83$ & $2 \cdot 25$ & $2 \cdot 28$ & $2 \cdot 19$ & 2.96 & $2 \cdot 88$ & $2 \cdot 81$ \\
\hline $1 \cdot 73^{b}$ & $1 \cdot 68^{\mathrm{ab}}$ & $1.97^{\mathrm{C}}$ & $1 \cdot 79$ & $1 \cdot 77$ & $1 \cdot 79$ & $2 \cdot 22$ & $2 \cdot 32$ & $2 \cdot 21$ & $2 \cdot 76$ & $2 \cdot 93$ & $2 \cdot 90$ \\
\hline $1 \cdot 74^{\mathrm{b}}$ & $1 \cdot 70^{\mathrm{ab}}$ & $1 \cdot 90^{\mathrm{bc}}$ & $1 \cdot 82$ & 1.90 & $1 \cdot 85$ & $2 \cdot 20$ & $2 \cdot 18$ & $2 \cdot 10$ & $2 \cdot 87$ & $3 \cdot 03$ & $2 \cdot 90$ \\
\hline & SE $0 \cdot 14$ & & & SE $0 \cdot 15$ & & & SE 0.33 & & & SE $0 \cdot 25$ & \\
\hline
\end{tabular}

a, b, c Means without a common superscript letter within filling class and parameter are significantly different $(P<0 \cdot 05)$

cluster attachment. OT concentration was elevated as compared with baseline in each single experimental cow at latest at $1 \mathrm{~min}$ after the start of pre-stimulation. The means of individual peak OT concentrations (independent of time of occurrence) did not differ between treatments (data not shown).

Milking characteristics in Experiment 1 (TMY, MMT, AMF) did not differ between treatments (data not shown), i.e. a prestimulation of 15,30 or 45 s combined with latency periods of $30 \mathrm{~s}$ or $45 \mathrm{~s}$ resulted in similar milking characteristics in these mid-lactating dairy cows which corresponds with the results of Experiment 2.

\section{Experiment 2}

Cows at three different lactational stages were classified based on their degree of udder filling during the actual milking, separately for morning and evening milkings. From the early lactation cows, 5 were in class $80-100 \%$, and 2 in class $60-80 \%$, respectively, both for morning and evening milking. Of the mid-lactation cows at morning milking, 3 were in class $60-80 \%$ and 4 in class $40-60 \%$, while for evening milkings 3 cows were in class $60-80 \%$, and 2 each in classes $40-60 \%$ and $20-40 \%$, respectively. Of the late lactation cows 5 were in class $40-60 \%$ for the morning milkings, and 2 in class $20-40 \%$ while at morning milkings 3 animals were in class $40-60 \%$ and 4 animals in class $20-40 \%$, respectively.
TMY (Table 1) did not differ between treatments in any udder filling class, i.e. the quality of udder emptying was similar independent of pre-stimulation time or latency period.

MMT and AMF (Table 1) did not differ between treatments in the filling classes 40-60, 60-80, and 80-100\%, respectively, i.e. at all milkings when the degree of udder filling was $>40 \%$. This finding was confirmed by the exemplary earlylactation cow (Fig. 2) where independent of treatment the milk flow curves were similar and non-bimodal. In the exemplary mid-lactation cow (Fig. 3) the milk flow curves were only bimodal if milking was started immediately after a 15-s pre-stimulation without a latency period, and after a latency period of $60 \mathrm{~s}$ following a pre-stimulation of $15 \mathrm{~s}$. However, treatment differences $(P<0 \cdot 05)$ were observed for these parameters in the filling class $20-40 \%$. MMT in class $20-40 \%$ (Table 1) was shortest at a latency period of $45 \mathrm{~s}$, independent of duration of pre-stimulation. Numerically the shortest MMT was observed after a 30-s pre-stimulation combined with a 45-s latency period. The longest MMT was observed if the cluster was attached immediately after pre-stimulation, and the numerically longest MMT was observed at a 15-s pre-stimulation without an additional latency period. AMF in class 20-40\% (Table 1) was highest after a pre-stimulation of $45 \mathrm{~s}$, followed by a latency period of another $45 \mathrm{~s}$. In contrast, AMF reached its lowest values at a pre-stimulation of $15 \mathrm{~s}$ without additional latency period. However, AMF after a 15-s pre-stimulation increased with increasing latency period following the pre-stimulation. The exemplary milk 


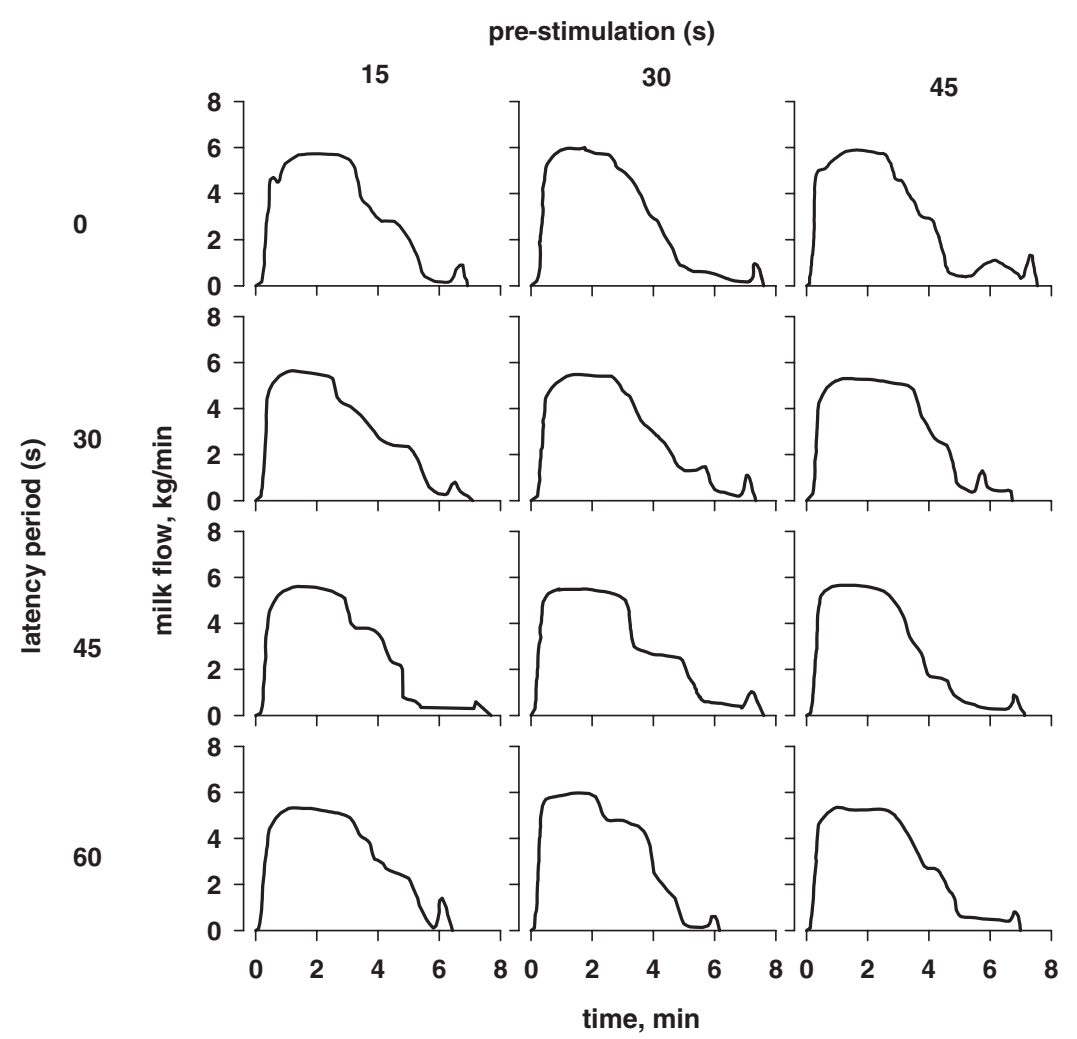

Fig. 2. Milk flow curves of one exemplary cow in early lactation (month 2, degree of udder filling 90-95\%) during milking in 12 different combinations of pre-stimulation and latency period.

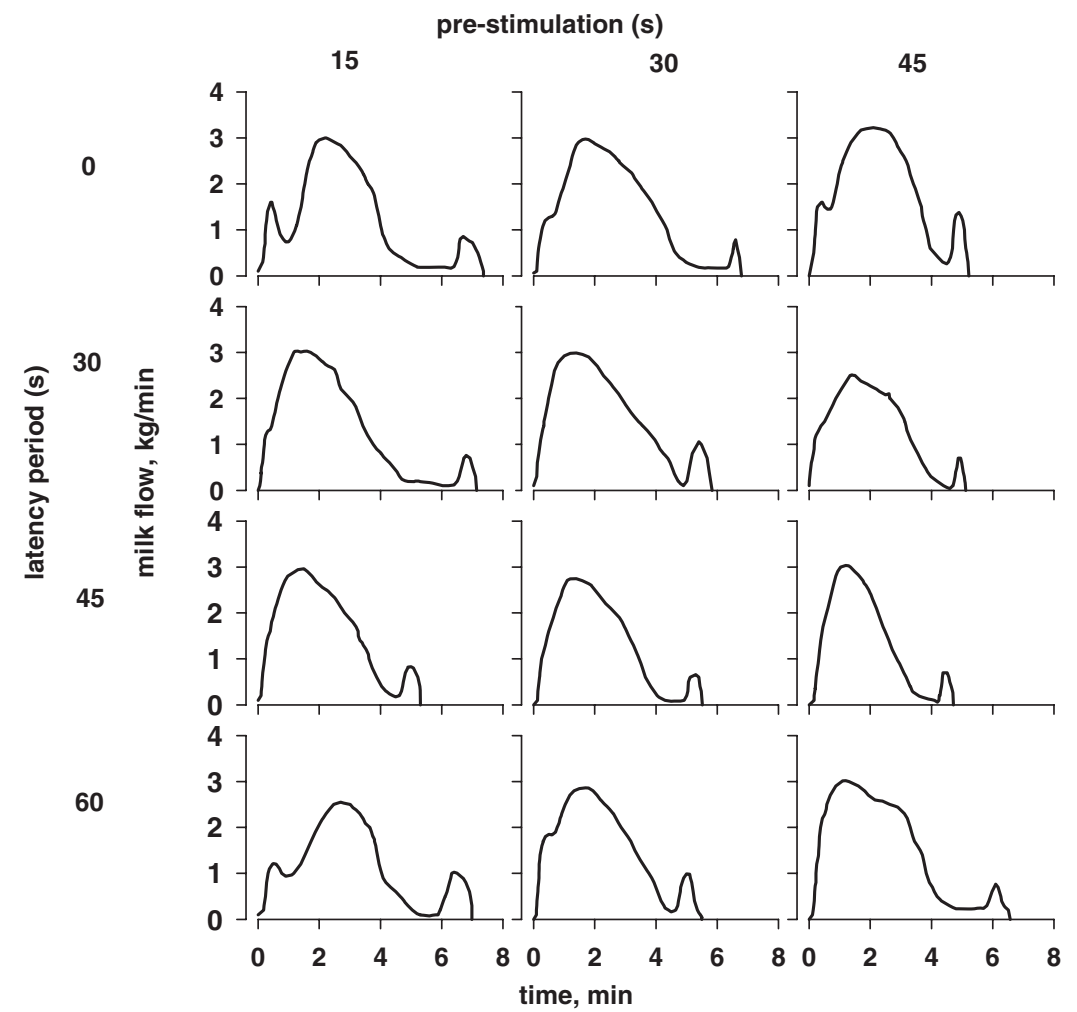

Fig. 3. Milk flow curves of one exemplary cow in mid lactation (month 5, degree of udder filling 46-51\%) during milking in 12 different combinations of pre-stimulation and latency period. 


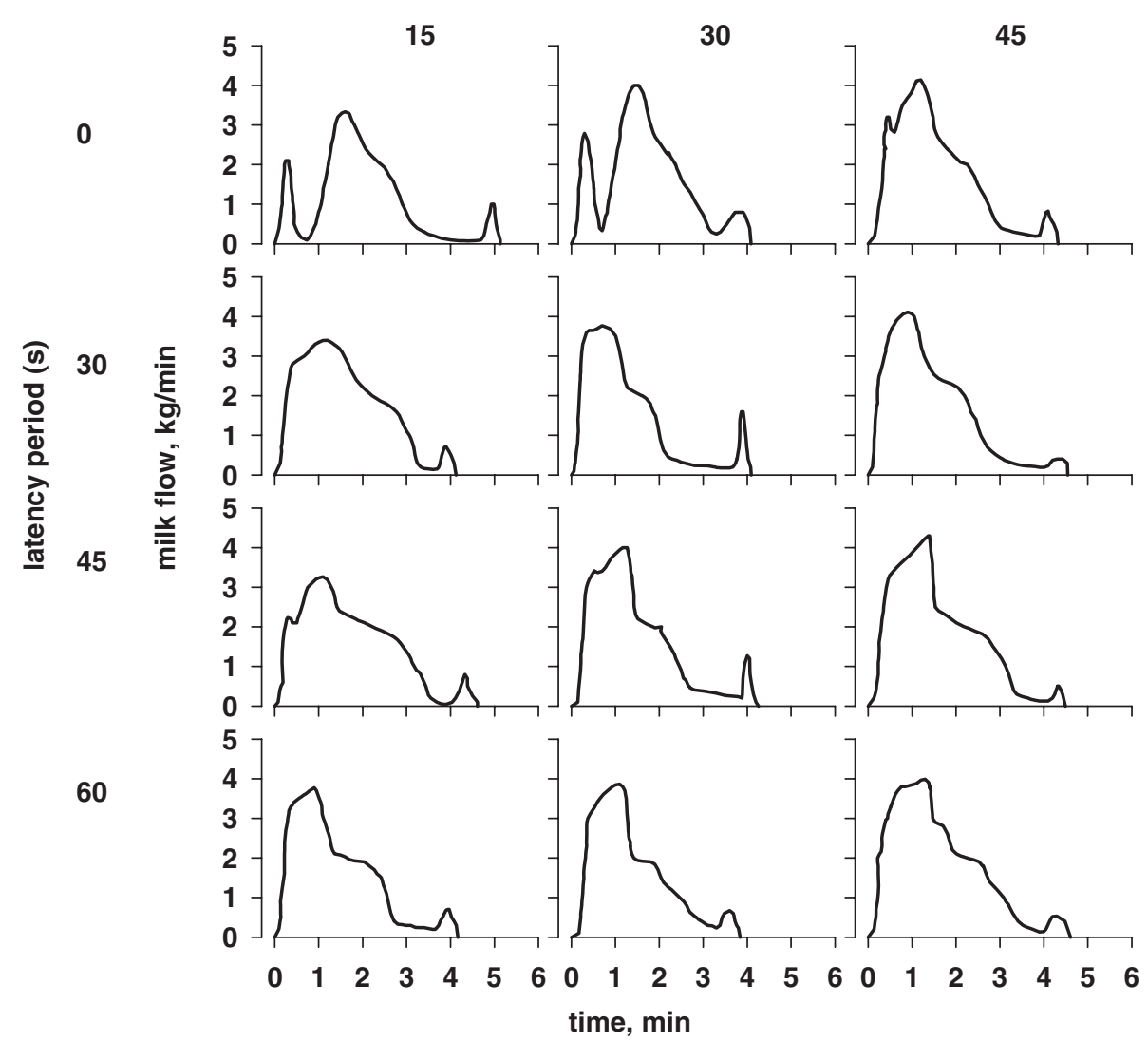

Fig. 4. Milk flow curves of one exemplary cow in late lactation (month 8, degree of udder filling 23-27\%) during milking in 12 different combinations of pre-stimulation and latency period.

flow curves from a cow in late lactation (Fig. 4) demonstrates that delayed milk ejection as represented by bimodal milk flow curves occurred at a pre-stimulation of $15 \mathrm{~s}$ or $30 \mathrm{~s}$, if the cluster was attached immediately without additional latency period. Bimodal milk flow was not observed if the pre-stimulation was followed by a latency period of minimum $30 \mathrm{~s}$.

\section{Discussion}

The results of the present study demonstrate that prestimulation before cluster attachment does not need to be continuous. Instead, a combination of a short prestimulation followed by a short latency period is suitable to induce milk ejection. It is generally accepted that complete udder emptying at milking requires OT release and alveolar milk ejection at the start of milking usually induced by prestimulation (Bruckmaier \& Blum, 1998). Because the shift of milk from the alveoli into the cistern before the start of milking is incomplete owing to the limited storage capacity of the cistern, the stimulatory effect must be maintained until the end of milking because milk ejection is a process that continues while milk is removed (Bruckmaier et al. 1994). Therefore, it is important that alveolar contraction is maintained during an interruption of the stimulatory effect between pre-stimulation and stimulation by the pulsating liner. A latency period of more than 2 min between a 1-min pre-stimulation and cluster attachment has been shown to be disadvantageous for udder emptying and milking characteristics (Mayer et al. 1984; Bruckmaier et al. 2001). However, only little information is available about the suitability of a shorter latency period up to 1 min following a short prestimulation. The few previous studies indicated that a short latency period before cluster attachment after a short prestimulation instead of continuous pre-stimulation causes normal or even improved milk removal (Rasmussen et al. 1992; Bruckmaier et al. 2001). The present study demonstrated that a teat-stimulation of $15 \mathrm{~s}$ is sufficient to induce OT release which is maintained without interruption until the end of milking if the cluster is attached no later than $45 \mathrm{~s}$ after the end of this 15 -s teat-stimulation. The previously shown negative effects of longer latency periods $>2$ min (Mayer et al. 1984) are obviously due to a decrease of OT based on the short bio-disponibility in blood (2-3 min) of this hormone (Wachs et al. 1984; Belo \& Bruckmaier, 2010). However, this study showed that a pre-stimulation as short as only $15 \mathrm{~s}$ requires a latency period to allow the occurrence of milk ejection before cluster attachment. Corresponding with earlier results, an immediate attachment after $15 \mathrm{~s}$ of pre-stimulation was only possible at a very high degree of udder filling, i.e. if a high amount of cisternal milk 
can bridge the short time until the early occurrence of milk ejection in well-filled udders (Bruckmaier \& Hilger, 2001; Weiss \& Bruckmaier, 2005). Thus, no significant differences between the used treatments on milk yield and milking characteristics were observed for well-filled udders. At low udder filling the stimulation of $15 \mathrm{~s}$ was sufficient, however only in combination with a latency period of at least $30 \mathrm{~s}$. If milking in udders with low degree of filling was started immediately after a 15-s manual teat stimulation the milk flow curves showed a clear transient decrease between the removal of the cisternal milk and the availability of the alveolar milk. In some cases milk flow curves at milking after a latency period of $60 \mathrm{~s}$ following a 15-s stimulation showed a transient depression after removal of available milk and before a renewed milk ejection (e.g. Fig. 3). Thus a latency period following a stimulation of $15 \mathrm{~s}$ should not be longer than $45 \mathrm{~s}$. If a longer time to induce milk ejection is needed, the pre-stimulation period should be increased to $30 \mathrm{~s}$ which allows also a combination with a subsequent latency period of up to $60 \mathrm{~s}$ (Fig. 4) or even a bit longer (not tested). Interestingly, pre-term cluster attachment after short prestimulation but without latency period did not affect milk yield but only caused a prolonged course of milk removal as shown by elevated main milking time and reduced average milk flow. This finding confirms our previous studies where omitting pre-stimulation caused only a delayed milk removal but not a reduced milk yield (Bruckmaier et al. 1995; Weiss \& Bruckmaier, 2005). The possibility to bridge the time until the occurrence of milk ejection by a latency period instead of continuing stimulation can cause a reduced mechanical load on the teat tissue and a relaxation of teat smooth muscles while milk ejection occurs. Therefore it is even possible that milk flow rates are higher if continuous stimulation is partially replaced by a latency period (Rasmussen et al. 1992; Bruckmaier et al. 2001). In practical milking, depending on the available milking system, this allows a short teat preparation in several animals in sequence, mainly consisting of pre-stripping and teat cleaning before the clusters are attached to these animals. In automatic milking systems a short interruption between teat cleaning (which has a strong stimulatory effect on milk ejection) and attachment of teat cups can usually not be avoided (Dzidic et al. $2004 a, b)$. Based on the results of the present study this interruption is rather an advantage than a disadvantage. Teat cleaning can be restricted to the time which is necessary to achieve clean teats while additional action of the teat cleaning device until occurrence of milk ejection is not required, thus also reducing the mechanical load on the teat tissue.

In conclusion, a combination of a short pre-stimulation with a short latency period instead of continuous stimulation before cluster attachment is suitable to induce milk ejection. However, it needs to be considered that the period until occurrence of milk ejection depends on the degree of udder filling. This period needs to be covered by the time of stimulation and latency period, i.e. the latency period is necessary if teat stimulation is short. A pre-stimulation of only $15 \mathrm{~s}$ allows a subsequent latency period of up to $45 \mathrm{~s}$. If milk ejection requires a longer period than $1 \mathrm{~min}$ e.g. at very low udder filling the duration of stimulation must be increased to $30 \mathrm{~s}$ to allow a subsequent latency period of up to $1 \mathrm{~min}$.

The expert performance of the radioimmunoassay for oxytocin by Mrs Yolande Zbinden, Veterinary Physiology, is gratefully acknowledged. This study was supported by the Swissmilk (SMP), Bern, Switzerland. The sabbatical stay of S Kaskous at the University of Bern was supported by a grant from the University of Damascus, Syria.

\section{References}

Ayadi M, Caja G, Such X, Rovai M \& Albanell E 2004 Effect of different milking intervals on the composition of cisternal and alveolar milk in dairy cows. Journal of Dairy Research 71 304-310

Belo CJ \& Bruckmaier RM 2010 Suitability of low dosage oxytocin treatment to induce milk ejection in dairy cows. Journal of Dairy Science 93 63-69

Belo CJ, Schlegel S, Moll J, Möstl E \& Bruckmaier RM 2009 Milk ejection disorders in Swiss dairy cows: a field study. Journal of Dairy Research $\mathbf{7 6}$ 222-228

Bruckmaier RM, Schams D \& Blum JW 1993 Milk removal in familiar and unfamiliar surroundings cocentration of oxytocin, prolactin and betaendorphin. Journal of Dairy Research 60 449-456

Bruckmaier RM, Schams D \& Blum JW 1994 Continuously elevated concentration of oxytocin during milking are necessary for complete milk removal in dairy cows. Journal Dairy Research 61 323-334

Bruckmaier RM, Rothenanger E \& Blum JW 1995 Milking characteristics in dairy cows of different breeds from different farms and during the course of lactation. Journal of Animal Breeding and Genetics 112 293-302

Bruckmaier RM \& Blum JW 1996 Stimultaneous recording of oxytocin release, milk ejection and milk flow during milking of dairy cows with and without prestimulation. Journal of Dairy Research 63 201-208

Bruckmaier RM \& Blum JW 1998 Oxytocin release and milk removal in ruminants. Journal of Dairy Science 81 939-949

Bruckmaier RM 2001 Milk ejection during machine milking in dairy cows. Livestock Production Science 70 121-124

Bruckmaier RM \& Hilger M 2001 Milk ejection in dairy cows at different degrees of udder filling. Journal of Dairy Research 68 369-376

Bruckmaier RM, Macuhova J \& Meyer HHD 2001 Specific aspects of milk ejection in robotic milking: A review. Livestock Production Science 72 169-176

Dzidic A, Macuhova J \& Bruckmaier RM 2004b Effects of cleaning duration and water temperature on oxytocin release and milk removal in an automatic milking system. Journal of Dairy Science $\mathbf{8 7}$ 4163-4169

Dzidic A, Weiss D \& Bruckmaier RM 2004a Oxytocin release, milk ejection and milking characteristics in a single stall automatic milking system. Livestock Production Science 86 61-68

Knight CH, Hirst D \& Dewhurst RJ 1994 Milk accumulation and distribution in the bovine udder during the interval between milkings. Journal of Dairy Research 61 167-177

Mayer H, Schams D, Prokopp A \& Worstorff H 1984 Effects of manual stimulation and delayed milking on secretion of oxytocin and milking characteristics in dairy cows. Milchwissenschaft 39 666-670

Mayer H, Worstorff H, Schams D \& Klein M 1985 Secretion of oxytocin and milking characteristics in cows as affected by several modes of tactile teat stimulation. Milchwissenschaft $401-5$

Pfeilsticker HU, Bruckmaier RM \& Blum JW 1996 Cisternal milk in the dairy cow during lactation and after preceding teat stimulation. Journal of Dairy Research 63 509-515

Rasmussen MD, Frimer ES, Horvath Z \& Jensen NE 1990 Comparison of a standardized and a variable milking routine. Journal of Dairy Science 73 3472-3480 
Rasmussen MD, Frimer ES \& Galton DM 1992 The influence of pre-milking teat preparation and attachment delay on milk yield and milking. Journal of Dairy Science 75 2131-2141

SAS Institute 1999 Manual, Version 8, Cary NC, USA

Schams D 1983 Oxytocin determination by radioimmunoassay. III. Improvement to subpicogram sensitivity and application to blood levels in cyclic cattle. Acta Endocrinologica 103 180-183

Tancin V, Ipema B, Hogewerf P \& Macuhova J 2006 Sources of variation in milk flow characteristics at udder and quarter levels. Journal of Dairy Science 89 978-988
Wachs EA, Gorewit RC \& Currie WB 1984 Half-life, clearance and production rate for oxytocin in cattle during lactation and mammary involution. Domestic Animal Endocrinology 1 121-140

Weiss D, Hilger M, Meyer HHD \& Bruckmaier RM 2002 Variable milking intervals and milk composition. Milchwissenschaft 57 246-250

Weiss D, Dzidic A \& Bruckmaier RM 2003 Effect of stimulation intensity on oxytocin release before, during and after machine milking. Journal of Dairy Research 70 349-354

Weiss D \& Bruckmaier RM 2005 Optimization of individual prestimulation in dairy cows. Journal of Dairy Science 88 137-147 